\title{
Sistem Informasi Pembelian Bahan Baku Sockliner pada PT Sinar Utama Jaya Abadi
}

\author{
Evita Sulis Tyanur ${ }^{1}$, Rachmat Hidayat $^{2}$, Yusnia Budiarti ${ }^{3}$
}

\begin{abstract}
The process of purchasing raw materials has an important role in the production process. Because the purchase of raw materials is an initial activity for the company to generate income. It is impossible in a company to provide itself with the need to run the wheels of the company. The problem that exists at this time is the process of purchasing raw materials, the process is still carried out conventionally, the Purchase Order (PO) is made using Microsoft Excel and then printed and sent to the supplier via email I fax, this is often an error in the process of data input and data storage not yet integrated by the system so that it is difficult when searching for data. Apart from that, in the production of goods receipt reports, goods demand reports and purchase reports, it takes a long time to process and combine a lot of data in Microsoft Excel. The purpose of this research is to simplify, speed up and reduce errors in the sockliner raw material purchasing system at PT Sinar Utama Jaya Abadi to help process purchasing data and company reports easily, quickly and accurately. The method used in this study is the SDLC waterfall model and in making this system, Visual Studio and MySQL are used. The result of the system that has been created is a sockliner raw material purchase information system that can manage purchasing data information.
\end{abstract}

Intisari- Proses pembelian bahan baku memiliki peranan penting dalam proses produksi. Karena pembelian bahan baku merupakan sebuah awal kegiatan perusahaan dalam menghasilkan pendapatan. Tidak mungkin dalam suatu perusahaan dapat menyediakan sendiri kebutuhan untuk menjalankan roda perusahaan. Permasalahan yang ada pada saat ini proses pembelian bahan baku prosesnya masih dilakukan secara konvensional, Purchase Order (PO) di buat dengan menggunakan Microsoft Excel lalu dicetak dan dikirim kepada supplier via email/fax, hal ini sering terjadi kesalahan pada proses input data dan penyimpanan data belum terintegrasi oleh sistem sehingga kesulitan pada saat pencarian data selain itu dalam pembuatan laporan penerimaan barang, laporan permintaan barang dan laporan pembelian memerlukan waktu yang cukup lama untuk mengolah dan menggabungkan banyak data dalam Microsoft Excel. Tujuan dari penelitian ini adalah agar mempermudah, mempercepat dan mengurangi kesalahan dalam sistem pembelian bahan baku sockliner pada PT Sinar Utama Jaya Abadi untuk membantu mengolah data pembelian serta laporan perusahaan dengan mudah, cepat dan akurat. Metode yang digunakan dalam penelitian ini adalah model SDLC air terjun (waterfall) dan dalam pembuatan sistem ini, menggunakan Visual Studio dan MySQL. Hasil dari sistem yang telah dibuat adalah berupa sistem informasi pembelian bahan baku sockliner yang dapat mengelola informasi data

Sistem Informasi ${ }^{12}$, Teknik Informatika ${ }^{3}$, Universitas Nusa Mandiri $^{13}$, Universitas Bina Sarana Informatika ${ }^{2}, \mathrm{Jl}$. Jatiwaringin Raya Jakarta Indonesia ${ }^{13}$, Jl.Kramat 98 Jakarta Indonesia ${ }^{2}$ e-mail: ${ }^{1}$ sulisevita@gmail.com,

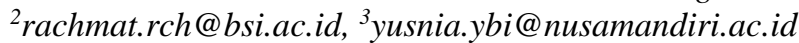

Kata Kunci- Sistem Informasi, Permintaan Barang, Pembelian Barang, Penerimaan Barang, Waterfall

\section{PENDAHULUAN}

Proses pembelian bahan baku memiliki peranan penting dalam proses produksi. Karena pembelian bahan baku merupakan sebuah awal kegiatan perusahaan dalam menghasilkan pendapatan. Tidak mungkin dalam suatu perusahaan dapat menyediakan sendiri kebutuhan untuk menjalankan roda perusahaan (Andryadi, 2017). PT Sinar Utama Jaya Abadi merupakan sebuah perusahaan yang bergerak di bidang manufaktur khususnya Sockliner, Upper, Sublimation, Printing Embos, PU Rubber, Laminating, Preparation, Digital Printing dan Cutting Press. PT Sinar Utama Jaya Abadi menjalin kerjasama dengan PT Panarub Industry yang sebagai Perusahaan di bidang manufaktur khususnya sepatu Adidas. Kerjasama ini dilakukan karena adanya saling keterkaitan antara sepatu dan sockliner yang tidak bisa dipisahkan.

Masalah yang dihadapi oleh bagian pembelian PT. Sinar Utama Jaya Abadi hingga saat ini ada pada proses pembelian bahan baku yaitu prosesnya masih dilakukan secara konvensional Purchase Order (PO) masih di input dengan menggunakan Microsoft Excel lalu dicetak dan dikirim kepada supplier via email/fax, hal ini sering terjadi kesalahan pada proses memasukkan data dan penyimpanan data belum terintegrasi oleh sistem sehingga kesulitan pada saat pencarian data selain itu dalam pembuatan laporan penerimaan barang, laporan request order dan laporan pembelian memerlukan waktu yang cukup lama untuk mengolah dan menggabungkan banyak data dalam Microsoft Excel karena sistemnya yang masih konvensional.

Dengan menggunakan teknologi bukan hanya sebagai proses otomatisasi terhadap akses informasi, tetapi juga menciptakan akurasi, kecepatan, dan kelengkapan sebuah sistem yang terintegrasi, sehingga proses terjadi akan efisien, terstuktur dan fleksibel. Penerapan pengolahan data pembelian bahan baku sangat diperlukan agar perusahaan dapat bertahan dan tangguh dalam menghadapi persaingan yang semakin ketat (Sauki, Warsino, \& Ardi, 2019).

Oleh sebab itu, perusahaan perlu membenahi sistem pembelian bahan baku agar mempermudah, mempercepat dan mengurangi kesalahan. Diharapkan dengan adanya sistem pembelian bahan baku sockliner ini dapat memberikan gambaran mengenai beberapa hal, yaitu gambaran yang dilakukan pada saat proses memasukkan data Purchase Order $(P O)$, proses request order, proses penerimaan barang, laporan penerimaan barang, laporan request order dan laporan pembelian. 


\section{TINJAUAN PUSTAKA}

Dalam menunjang proses perancangan Sistem Informasi pembelian bahan baku Sockliner diperlukan penjelasan teori yang dapat mendukukng dan menunjang keberhasilan dalam pembuatan sistem informasi. Berikut adalah beberapa teori yang berhubungan dengan penelitian sebagai berikut:

a. Pengertian Sistem

Sistem adalah kumpulan dari beberapa komponen yang saling berhubungan dan saling berkaitan sebagai satu kesatuan organik untuk mencapai suatu tujuan yang sama dan dapat mempengaruhi sebagian bahkan sampai mempengaruhi keseluruhan (Siregar, 2017).

b. Konsep Dasar Sistem Informasi

Sistem informasi yaitu suatu sistem dimana didalamnya terdapat suatu organisasi yang saling mempertemukan keutuhan pengolahan data transaksi harian untuk menunjang fungsi organisasi yang bersifat manajerial dengan kegiatan stategi pada organisasi untuk menyediakan laporan yang diperlukan oleh pihak tertentu (Uswara \& Patrie, 2019). Sistem informasi adalah kumpulan dari perangkat keras (hardware) dan perangkat lunak (software) komputer serta perangkat manusia (brainware) yang akan mengolah data menggunakan perangkat keras (hardware) dan perangkat lunak (software) tersebut. Data memiliki peranan yang sangat penting dalam sebuah sistem informasi. Data yang akan dimasukkan dalam sebuah sistem informasi dapat seperti prosedur-prosedur, formulir-formulir dan bentuk data lainnya (Kristanto, 2018).

c. Konsep Dasar Pemrograman Visual

Visual Basic merupakan high-level programming. Highlevel programming adalah pemrograman yang telah menggunakan syntax (perintah dan struktur pemrograman) "bahasa manusia" sehingga mudah dimengerti, terutama oleh orang yang baru belajar tentang bahasa pemrograman. Visual Studio biasa disebut dengan istilah Integrated Development Environment atau yang disingkat IDE. Selain Visual Basic juga bekerja dengan bahasa pemrograman lainnya, seperti $\mathrm{C \#}$ dan $\mathrm{C}++$, bersama-sama dengan script Visual Basic untuk membuat aplikasi yang lebih kompleks (Enterprise, 2017).

d. Blackbox Testing

Black-box testing juga disebut behavioral testing pengujian yang berfokus pada persyaratan fungsional dari perangkat lunak. Berarti, teknik pengujian black-box pengujian untuk memperoleh kondisi input yang sepenuhnya untuk melaksanakan semua persyaratan fungsional suatu program (Hardiyanto, Abdussomad, Haryadi, Sopandi, \& Asep, 2019).

e. MySQL

MySQL adalah software RDBMS (atau server database) yang dapat menjalankam database dengan sangat cepat, serta dapat diakses oleh banyak user (multi-user) dan dapat dilakukan secara sinkron atau berbarengan (multithreaded), serta dapat menyimpan data dalam jumlah yang banyak. Sebagai database server yang mampu untuk memanejemen database dengan baik, MySQL merupakan database yang paling digemari dan paling banyak digunakan dibanding database lainnya. Selain MySQL masih banyak lagi jenis database server yang memiliki kemampuan mumpuni dan juga tidak bisa dianggap gampang, database itu adalah Oracle dan PostgreSQL (Raharjo, 2018).

\section{METODE PENELITIAN}

Dalam metode pengembangan sistem, penulis menggunakan metode waterfall. Model SDLC air terjun (waterfall) sering juga disebut model air skuensial linier (sequential linear) atau alur hidup klasik (classic life cycle). Model air terjun memiliki pendekatan alur hidup perangkat lunak secara sekuensial atau terurut dimulai dari analisa, design, pengodean, pengujian, dan tahap pendukung (support). Berikut adalah model air terjun (waterfall).

a. Analisa Kebutuhan Sistem

Pada tahapan ini penulis melakukan proses analisa tentang permasalahan secara lebih mendetail terhadap sistem yang terjadi saat ini pada PT Sinar Utama Jaya Abadi. Serta bagaimana pemecahan masalah yang dihadapi dengan menganalisa beberapa dokumen yang penulis dapat dari hasil observasi, wawancara dan studi pustaka.

b. Desain

Tahapan desain penulis menggunakan Software Architecture untuk memodelkan sistem dirancang menggunakan ERD (Entity Relationship Diagram), Unified Modeling Language (UML) berserta Data Modeling yang akan digambarkan melalui beberapa diagram diantaranya: use case diagram, activity diagram dan component diagram.

c. Pembuatan Kode Program (Code Generation)

Pada tahap pembuatan kode program, penulis menggunakan bahasa pemprograman untuk pembuatan sistem informasi berbasis desktop yaitu VB.Net dan untuk pembuatan database menggunakan bahasa MySQL Server 5.7 ditambah dengan Open database Connectivity (ODBC) sebagai penghubung antara VB.Net dan database.

d. Pengujian (Testing)

Metode pengujian blackbox memfokuskan pada keperluan fungsional dan output. Pengujian blackbox berusaha untuk menemukan kesalahan dalam fungsi-fungsi yang salah atau hilang. Secara umum penguji melakukan test dengan tidak mengetahui proses bisnisnya. Pada tahapan testing penulis melakukan uji coba hanya menggunakan metode blackbox testing.

e. Pendukung (Support)

Untuk mendukung pembuatan sistem informasi berbasis desktop penulis menggunakan Microsoft Visual Studio untuk pembuatan halaman login, menu utama, master barang, master supplier, request order, po supplier, penerimaan barang, laporan penerimaan barang, laporan request order, laporan pembelian, autorisasi pengguna dan rubah kata sandi. Mysql Server 5.7 sebagai database server 
dan crystal report 8.5 sebagai pengolah data untuk menampilkan data laporan per periode. Untuk Sistem yang dibangun hanya support pada Komputer atau Laptop.

\section{PEMBAHASAN DAN HASIL}

4.1 Analisa Kebutuhan Sistem

Dalam analisa kebutuhan merupakan awal untuk menentukan gambaran perangkat yang akan dihasilkan.

A. Tahapan Analisa

Sistem Informasi Pembelian Bahan Baku Sockliner adalah aplikasi pembelian bahan baku sockliner berbasis desktop dimana sistem pembelian bahan baku sockliner dibagi menjadi tiga bagian yaitu request order, Purchase Order (PO) dan Penerimaan barang. Untuk tahapan request order pada aplikasi sistem pembelian bahan baku, Purchasing melalui aplikasi yang sudah ada dikomputer yang sudah terhubung kedalam jaringan intranet perusahaan, lalu membuka menu transaksi request order dan menginput data barang sesuai permintaan Production Planning and Inventory Control (PPIC).

Kemudian pada pengisian Purchase Order (PO), Purchasing login pada aplikasi tersebut lalu membuka menu transaksi Purchase Order (PO) dan menginput Purchase Order (PO) sesuai dengan Request Order. Sedangkan pada penerimaan barang, admin Warehouse login pada aplikasi tersebut lalu membuka menu transaksi penerimaan barang dan menginput data penerimaan barang sesuai dengan surat jalan yang dibawa oleh supplier.

\section{B. Use Case Diagram}

Use case bekerja dengan cara mendeskripsikan tipe interaksi antar pengguna sebuah sistem dengan sistemnya sendiri melalui sebuah cerita bagaimana sebuah sistem dipakai. Berikut dapat dilihat pada gambar di bawah ini:

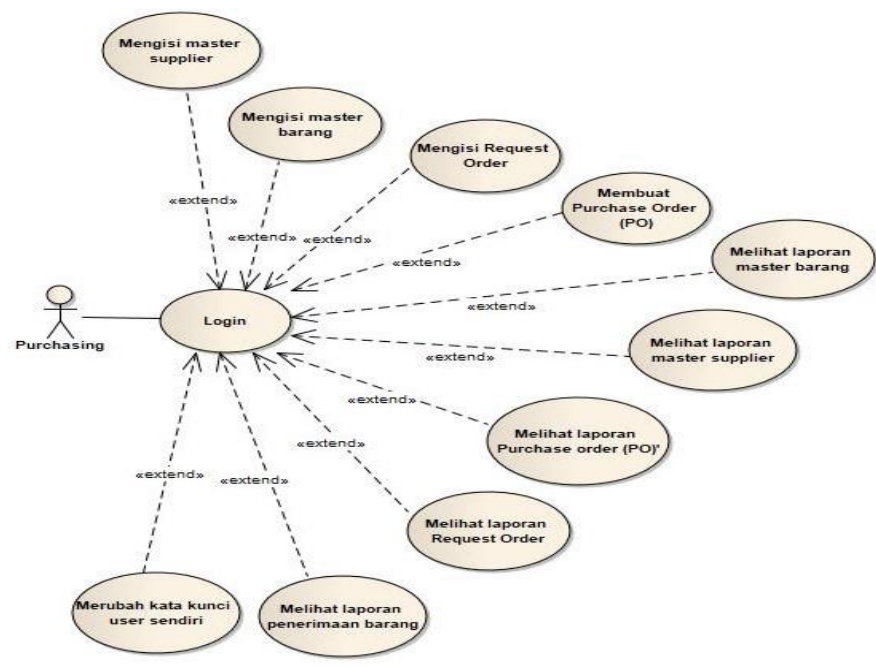

Gambar 1. Use Case Diagram Purchasing

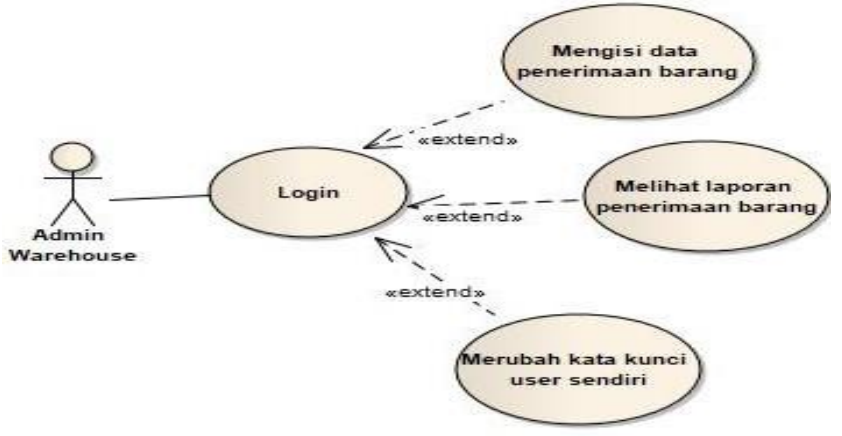

Gambar 2. Use Case Diagram Admin Warehouse

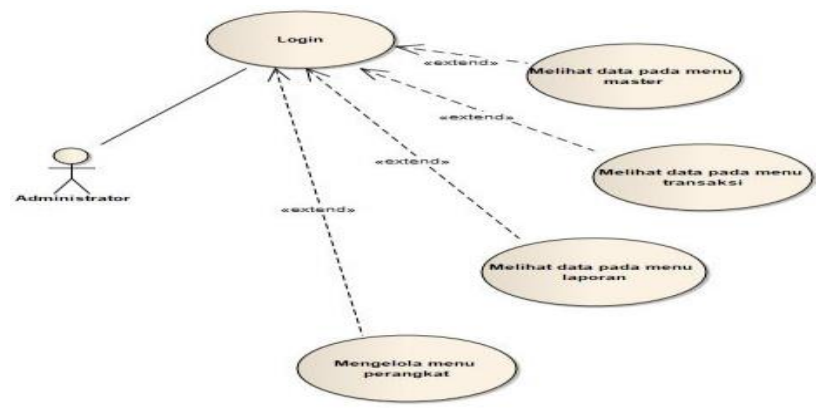

Gambar 3. Use Case Diagram Administrator

\section{Activity Diagram}

Activity Diagram digunakan untuk menggambarkan berbagai alir aktivitas dalam sistem yang sedang dirancang, bagaimana masing- masing berawal, decision yang mungkin terjadi dan bagaimana proses - proses tersebut selesai. Berikut dapat dilihat pada gambar dibawah ini:

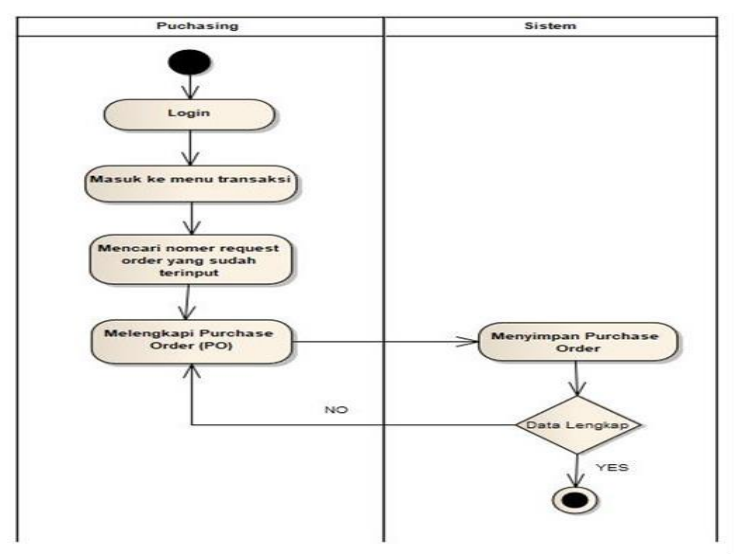

Gambar 4. Activity Diagram Purchasing mengelola Purchase Order (PO) 


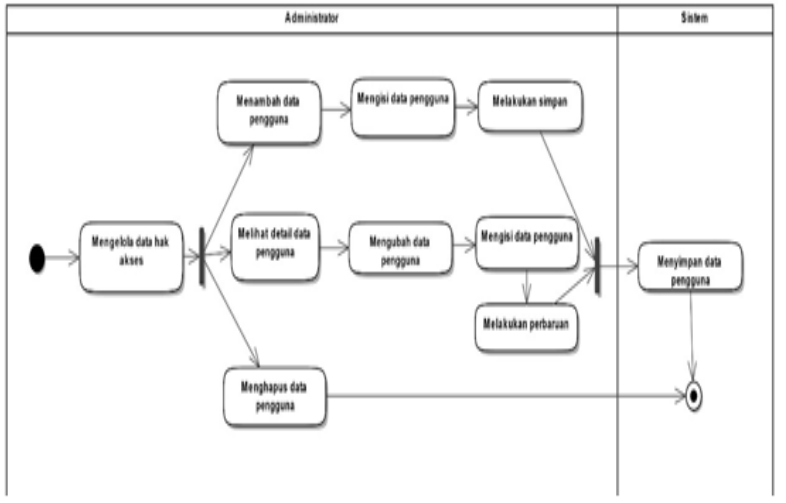

Gambar 5. Activity Diagram Administrator Mengelola Data Hak Akses

4.2 Desain

Pada tahap ini dilakukan pembuatan model dari perangkat lunak untuk memperoleh pengertian yang lebih baik terhadap aliran data dan kontrol, proses - proses fungsional, tingkah laku operasi dan informasi - informasi di dalamnya. Terdiri dari aktivitas utama pemodelan proses, pemodelan data dan desain antarmuka.

4.2.1 Database

1. Entity Relationship Diagram (ERD)

Pemodelan awal basis data paling banyak disukai yaitu menggunakan Entity Relation Diagram (ERD). ERD dikembangkan berdasarkan teori himpunan dalam bidang matematika. ERD diterapkan untuk pemodelan basis relasional. Ada beberapa metode perancangan ERD menoleransi hubungan $\mathrm{N}$-ary (satu relasi menghubungkan banyak entitas) atau relasi ternary (satu relasi menghubungkan tiga buah relasi) tapi banyak metode perancangan ERD yang tidak mengizinkan hubungan terary ataun N-ary (Sukamto \& Shalahuddin, 2018). Berikut merupakan hasil rancangan ERD dapat dilihat pada gambar di bawah ini

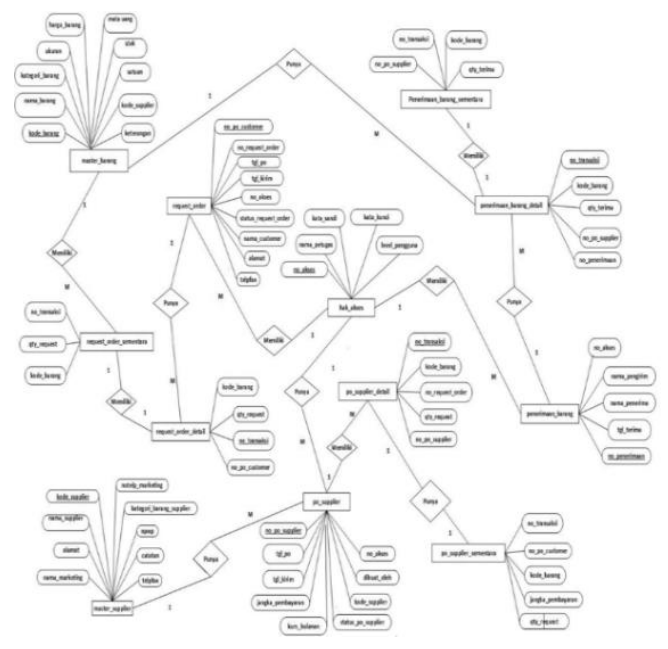

Gambar 6. Entity Relationship Diagram

\section{Logical Record Structure (LRS)}

Logical Record Structure (LRS) merupakan sebuah model sistem yang menggambarkan sebuah diagram-ER yang akan mengikuti aturan atau pola pemodelan tertentu yang kaitannya dengan konvensional ke LRS (Yunita \& Safitri, 2019). Berikut merupakan hasil rancangan LRS dapat dilihat pada gambar di bawah ini:

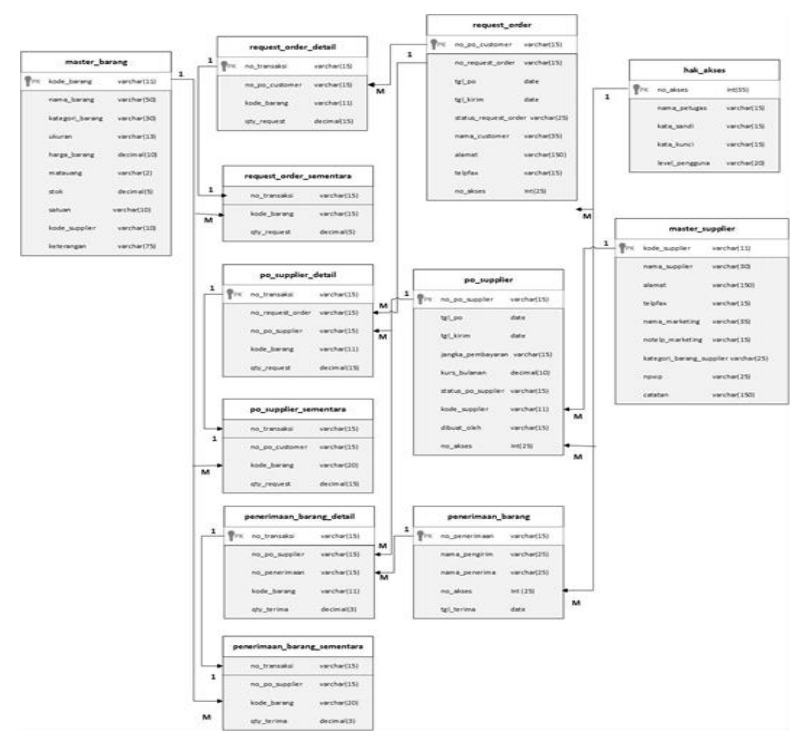

Gambar 7. Logical Record Structure

\subsubsection{Software Architecture}

A. Component Diagram

Diagram komponen atau component diagram adalah diagram yang menggambarkan struktur fisik dari sebuah sistem dan digunakan untuk mengilustrasikan bagaimana kode program (Munawar, 2018).

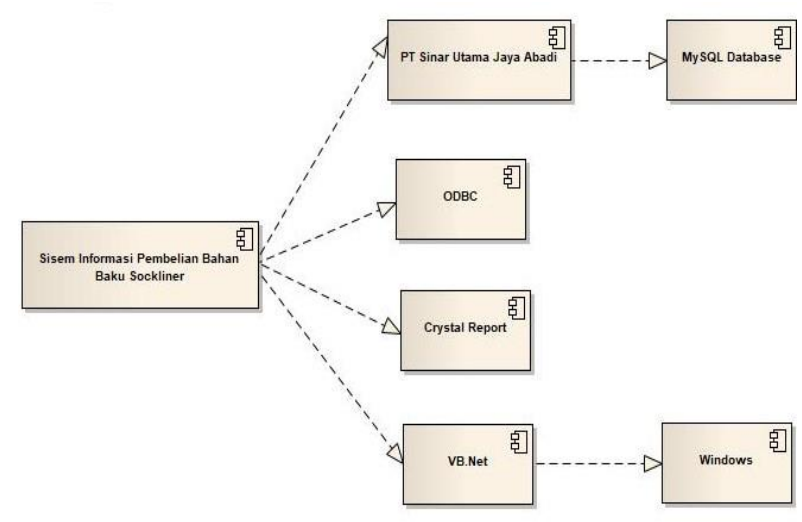

Gambar 8. Component Diagram

\section{B. Deployment Diagram}

Diagram deployment atau deployment diagram digunakan untuk mendokumentasikan proses yang terjadi pada sistem perangkat lunak yang akan dibangun serta menunjukkan 
konfigurasi komponen dalam proses eksekusi aplikasi (Munawar, 2018).

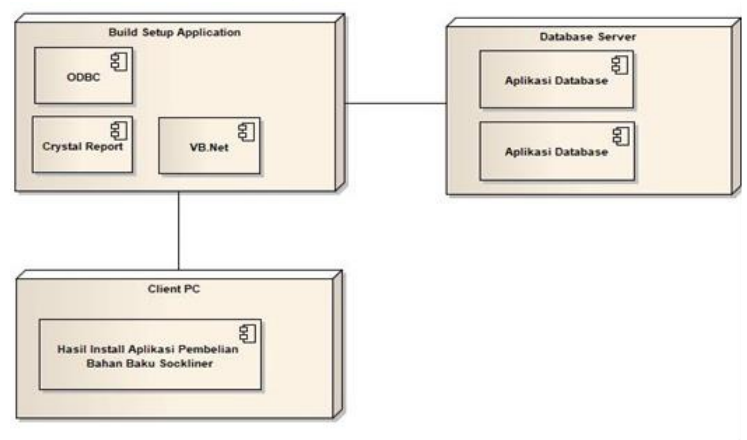

Gambar 9. Deployment Diagram

\subsubsection{User Interface}

Beberapa desain User Interface sistem ususlan yang ada pada PT Sinar Utama Jaya Abadi, diantaranya yaitu:

A. Tampilan Halaman Login

Halaman login merupakan tampilan awal pengguna untuk masuk kedalam aplikasi Sistem Informasi Pembelian Bahan Baku Sockliner. Pengguna harus memasukkan usename dan password untuk masuk ke menu. Halaman login dapat dilihat pada gambar 10 dibawah ini.

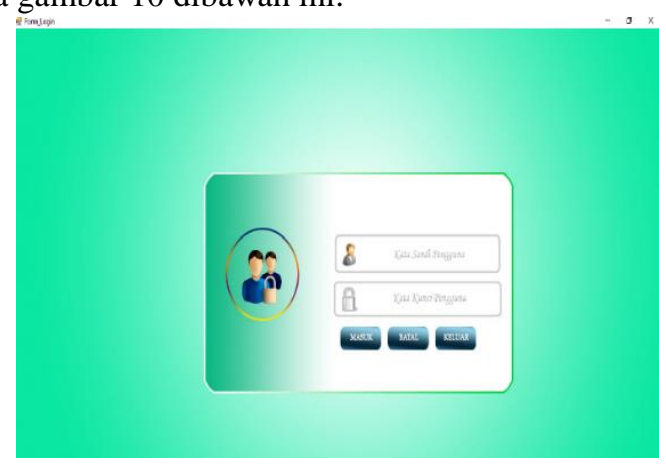

Gambar 10. Halaman Login

B. Tampilan Menu Utama

Tampilan laman menu utama ialah tampilan utama yang didalamnya terdapat data master, data transaksi, data laporan dan perangkat. Tampilan menu utama dapat dilihat pada gambar 11 dibawah ini.

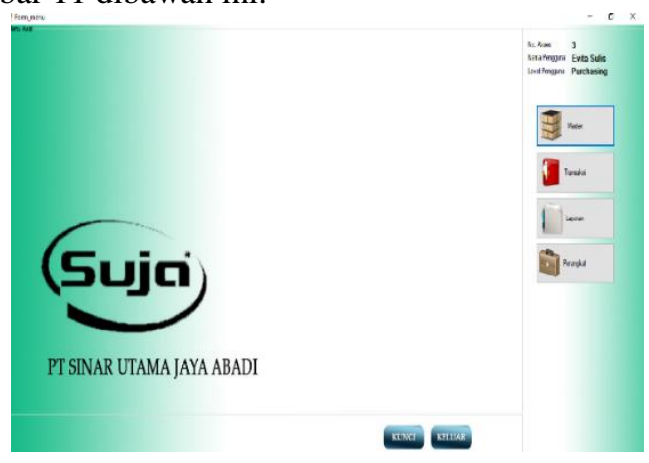

Gambar 11. Halaman Menu Utama
C. Tampilan Menu Master Barang

Tampilan menu master barang merupakan tampilan dimana user dapat melakukan proses pengolahan data barang. Tampilan data obat yang dibuat dapat dilihat pada gambar 12 dibawah ini.

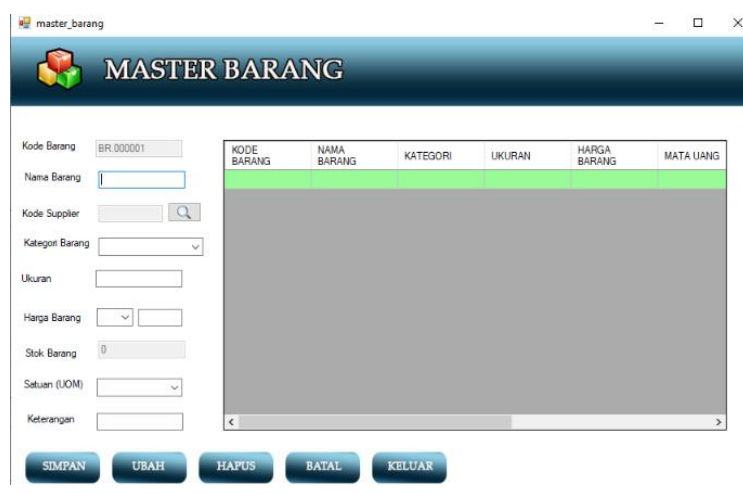

Gambar 12. Halaman Menu Master Barang

D. Tampilan Menu Master Supplier

Tampilan menu master supplier merupakan tampilan dimana user dapat melakukan proses pengolahan data supplier. Tampilan data obat yang dibuat dapat dilihat pada gambar 13 dibawah ini.

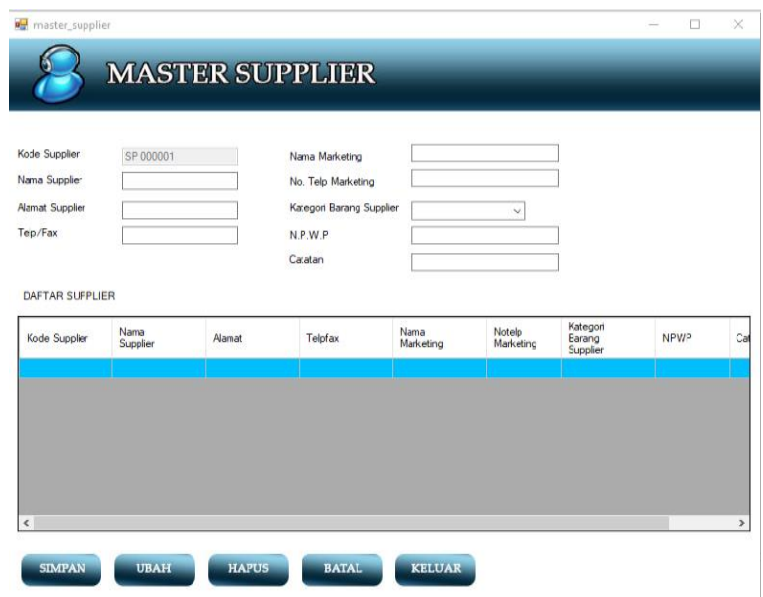

Gambar 13. Halaman Master Supplier

E. Tampilan Transaksi Purchasing Order (PO)

Tampilan transaksi Purchasing Order (PO) ialah tampilan yang digunakan untuk memasukkan data pembelian dapat dilihat pada gambar 14 . 


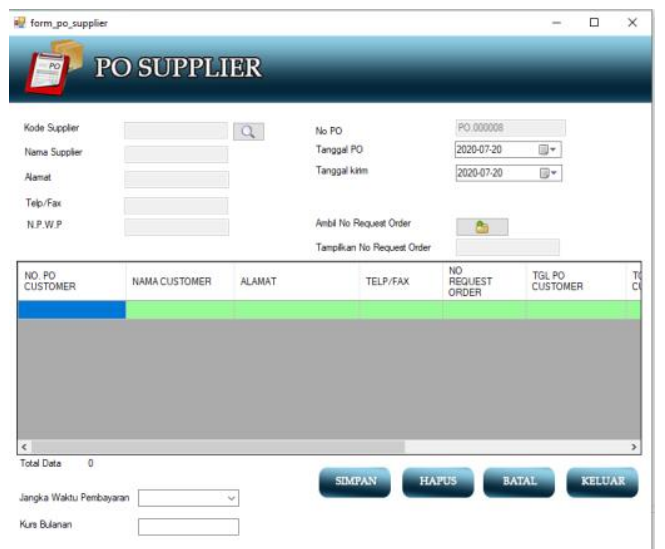

Gambar 14. Halaman Transaksi Purchasing Order (PO)

F. Tampilan Transaksi Request Order

Tampilan transaksi request order ialah tampilan yang digunakan untuk memasukkan data request order atau permintaan pembelian dapat dilihat pada gambar 15 .

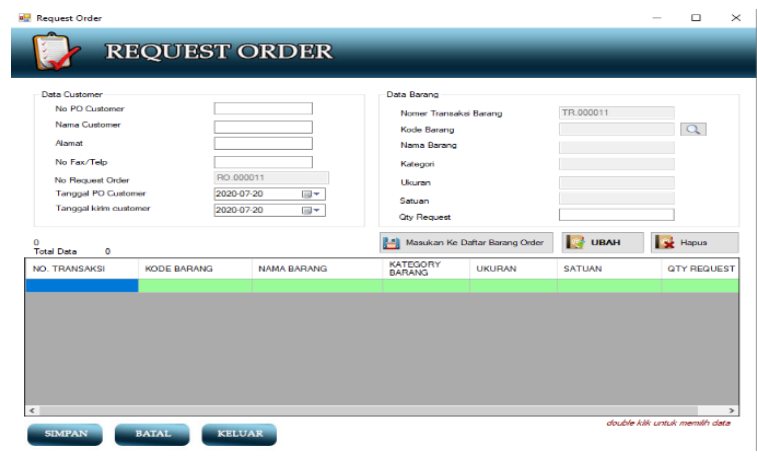

Gambar 15. Halaman Transaksi Request Order

G. Tampilan Transaksi Penerimaan Barang

Tampilan transaksi penerimaan barang ialah tampilan yang digunakan untuk memasukkan data penerimaan barang dapat dilihat pada gambar 16.

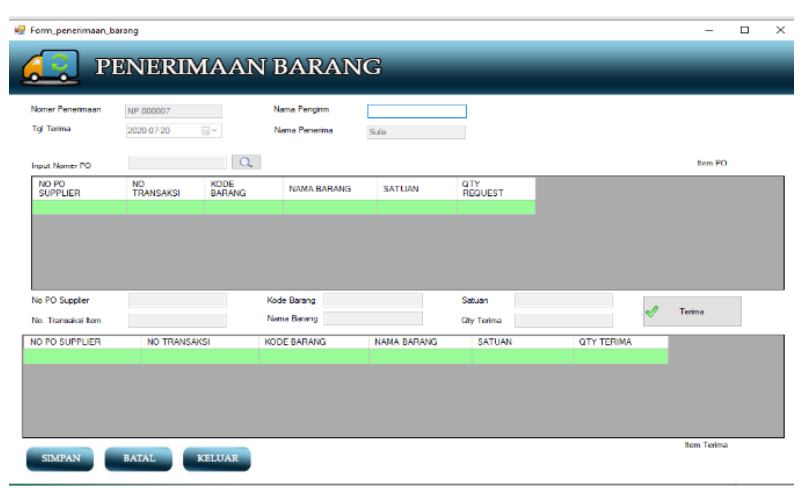

Gambar 16. Halaman Transaksi Penerimaan Barang
H. Tampilan Laporan Transaksi Purchasing Prder (PO) Tampilan laporan transaksi purchasing order di lihat oleh user dapat dilihat pada gambar 17.

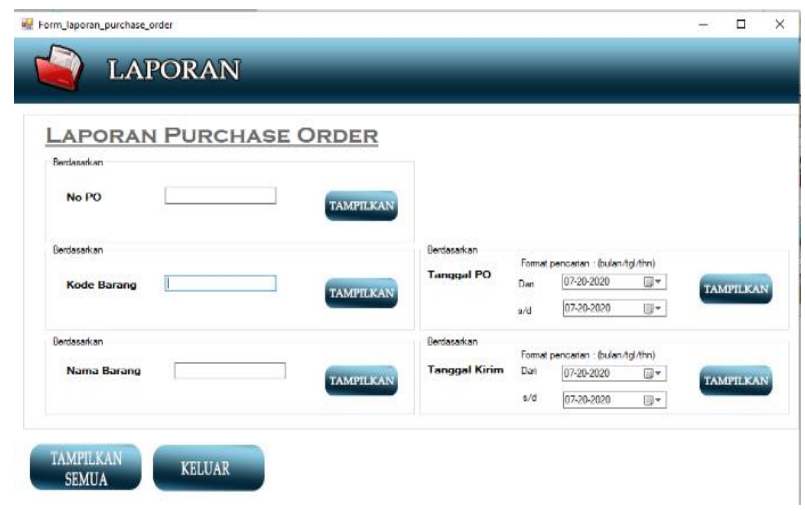

Gambar 17. Halaman Laporan Purchasing Order (PO)

4.3 Testing

Pada tahapan ini, dilakukan pengujian dengan Black Box Testing untuk memastikan sistem yang sudah dibuat telah sesuai dengan desainnya dan semua fungsi dapat berjalan dengan baik, berikut hasil pengujian dari Black box testing. 


\begin{tabular}{|c|c|c|c|c|}
\hline $\begin{array}{l}\mathrm{N} \\
\mathrm{O}\end{array}$ & $\begin{array}{l}\text { Skenario } \\
\text { Pengujian }\end{array}$ & $\begin{array}{l}\text { Test } \\
\text { Case }\end{array}$ & $\begin{array}{l}\text { Hasil yang } \\
\text { diharapkan }\end{array}$ & $\begin{array}{l}\text { Hasil } \\
\text { Pengujian }\end{array}$ \\
\hline 1. & $\begin{array}{l}\text { Mengoson } \\
\text { gkan } \\
\text { semua } \\
\text { isian data } \\
\text { textbox } \\
\text { kata kunci } \\
\text { dan kata } \\
\text { sandi, lalu } \\
\text { klik } \\
\text { tombol } \\
\text { "Masuk". }\end{array}$ & $\begin{array}{l}\text { Kata } \\
\text { kunci: } \\
\text { (koson } \\
\text { g) } \\
\text { Kata } \\
\text { sandi: } \\
\text { (koson } \\
\text { g) }\end{array}$ & $\begin{array}{lr}\text { Sistem akan } \\
\text { menolak akses } \\
\text { masuk dan } \\
\text { menampilkan } \\
\text { pesan "Kata } \\
\text { Kunci Dan Kata } \\
\text { Sandi Tidak } \\
\text { Boleh Kosong". }\end{array}$ & $\begin{array}{l}\text { Sesuai } \\
\text { harapan }\end{array}$ \\
\hline 2. & $\begin{array}{l}\text { Hanya isi } \\
\text { data kata } \\
\text { kunci dan } \\
\text { mengoson } \\
\text { gkan data } \\
\text { kata sandi, } \\
\text { lalu klik } \\
\text { tombol"M } \\
\text { asuk". }\end{array}$ & $\begin{array}{l}\text { Kata } \\
\text { kunci: } \\
\text { (benar) } \\
\text { Kata } \\
\text { sandi: } \\
\text { (koson } \\
\text { g) }\end{array}$ & $\begin{array}{lr}\text { Sistem akan } \\
\text { menolak akses } \\
\text { masuk dan } \\
\text { menampilkan } \\
\text { pesan "Kata } \\
\text { Kunci Atau Kata } \\
\text { Sandi Tidak } \\
\text { Boleh Kosong" }\end{array}$ & $\begin{array}{l}\text { Sesuai } \\
\text { harapan }\end{array}$ \\
\hline 3. & $\begin{array}{l}\text { Mengisi } \\
\text { data } \\
\text { dengan } \\
\text { kata kunci } \\
\text { yang tidak } \\
\text { sesuai } \\
\text { sebanyak } \\
3 \text { kali, lalu } \\
\text { klik } \\
\text { tombol } \\
\text { "Masuk". }\end{array}$ & $\begin{array}{l}\text { Kata } \\
\text { kunci: } \\
\text { (salah) } \\
\text { Kata } \\
\text { sandi: } \\
\text { (benar) }\end{array}$ & $\begin{array}{lr}\text { Sistem akan } \\
\text { menolak akses } \\
\text { masuk dan } \\
\text { menampilkan } \\
\text { pesan "Kata } \\
\text { Kunci Atau Kata } \\
\text { Sandi Anda } \\
\text { Salah" dan akan } \\
\text { menutup } \\
\text { aplikasi jika } \\
\text { terjadi kesalahan } \\
\text { kata kunci } \\
\text { sebanyak } 3 \text { kali } \\
\text { dan } \\
\text { menampilkan } \\
\text { pesan "Maksimal } \\
\text { Kesalahan Login } \\
\text { Hanya } 3 \text { Kali }\end{array}$ & $\begin{array}{l}\text { Sesuai } \\
\text { harapan }\end{array}$ \\
\hline 4. & $\begin{array}{l}\text { Isi data } \\
\text { pengguna } \\
\text { yang } \\
\text { benar lalu } \\
\text { klik } \\
\text { tombol } \\
\text { "Masuk". }\end{array}$ & $\begin{array}{l}\text { Kata } \\
\text { kunci: } \\
\text { (benar) } \\
\text { Kata } \\
\text { sandi: } \\
\text { (benar) }\end{array}$ & $\begin{array}{lr}\text { Sistem akan } \\
\text { menerima akses } \\
\text { Masuk dan } \\
\text { kemudian } \\
\text { langsung } \\
\text { menampilkan } \\
\text { menu halaman } \\
\text { utama }\end{array}$ & $\begin{array}{l}\text { Sesuai } \\
\text { harapan }\end{array}$ \\
\hline
\end{tabular}

Tabel 1. Pengujan Black Box Testing

\section{KESIMPULAN DAN SARAN}

Dari uraian tentang sistem informasi pembelian bahan baku sockliner berbasis desktop pada PT Sinar Utama Jaya Abadi yang merupakan hasil dari pengamatan dan perancangan program desktop tersebut Berikut ini beberapa kesimpulan yang dapat penulis ambil yaitu:

1. Dengan adanya sistem informasi pembelian bahan baku sockliner berbasis desktop ini merupakan sarana yang efektif dan mempermudah untuk mengolah data pembelian sampai laporan.

2. Sistem informasi pembelian ini memudahkan penginputan data pembelian barang dan penerimaan barang karena sebelumnya pembuatan data masih dilakukan secara konvensional menggunakan Microsoft Excel dengan mencari data satu persatu.

3. Memudahkan bagian Purchasing dan warehouse dalam pencarian data pembelian, penerimaan barang serta pembuatan laporan dengan cepat dan tepat waktu.

4. Dapat dengan mudah melakukan proses backup data serta pemanggilan data yang sudah tersimpan kedalam aplikasi sistem pembelian bahan baku scokliner.

Adanya saran-saran yang penulis kemukakan kaitannya dengan kesimpulan dalam pembuatan program sistem informasi pembelian bahan baku sockliner sebagai berikut:

1. Diharapkan agar pengelolaan data oleh Purchasing dan warehouse dilakukan dengan baik dan teliti, guna meminimalisir kesalahan dalam penginputan data. Karena itu, maka dibutuhkan tenaga kerja yang professional dalam bidang tersebut dalam masalah input data.

2. Pengembangan sistem pada pembelian bahan baku terkomputerisasi selanjutnya harus lebih baik jika menggunakan Bahasa program yang mampu memberikan kestabilan dalam penggunaannya.

3. Perawatan pada perangkat keras (hardware) dan perangkat lunak (software) sebaiknya dilakukan secara rutin.

4. Menambah ruang penyimpanan yang berbeda seperti hardisk external untuk melakukan proses backup data jika sewaktu-waktu terjadi hilangnya data atau rusaknya penyimpanan pada sisi server. Serta pekerjaan tambahan kepada 1 orang karyawan yang bertanggung jawab khusus untuk melakukan proses backup data seperti Information Technology $(I T)$.

\section{REFERENSI}

[1] A. A. Andryadi, "Perancangan Sistem Informasi Purchase Orderinternal Non Related Product Berbasis Web (Studi Kasus : PT. Shafco Multi Trading)," MEDIA Inform., vol. 16, no. 1, pp. 57-69, 2017.

[2] A. Sauki, Warsino, and Y. M. Ardi, "Perancangan Sistem Informasi Pembelian Bahan Baku Pada Pt Nani Wahyuni Industries Bekasi," J. Ilm. SANTIKA, vol. 9, no. 1, pp. 865-872, 2019. 
[3] V. M. M. Siregar, "Sistem Informasi Pembelian dan Penjualan Pakaian pada Galoenk Distro Pematang Siantar," J. Chem. Inf. Model., vol. 53, no. 49, pp. 13-26, 2017.

[4] D. Uswara and H. Patrie, "Perancangan sistem informasi pembelian dan penjualan toko elisa rizki dengan metodologi berorientasi obyek," IDEALIS, vol. 2, pp. 297-301, 2019.

5] A. Kristanto, Perancangan Sistem Informasi Dan Aplikasinya. Klaten: Gava Media, 2018.

[6] J. Enterprise, Otodidak Visual Basic. PT Elex Media Komputindo, 2017.

[7] Hardiyanto, Abdussomad, E. Haryadi, R. Sopandi, and Asep, "Penerapan Model Waterfall dan UML Dalam Rancang Bangun Program Pembelian Barang Berorientasi Objek pada PT Fujita Indonesia," INTERKOM, vol. 13, pp. 1-12, 2019.

[8] Raharjo, Belajar Otodidak MySQL. Informatika Bandung, 2018.

[9] R. A. Sukamto and M. Shalahuddin, Rekayasa Perangkat Lunak Terstruktur dan Berorientasi Objek. Bandung: Informatika Bandung, 2018.

[10] E. R. Yunita and N. Safitri, "Sistem Informasi Pengadaan Bahan Baku Berbasis Desktop Pada PT Inti Technik Sejahtera Bekasi," Inf. Syst. Educ. Prof., vol. 4 No.1, no. 1, pp. 85-94, 2019.

[11] Munawar, Analisa Perancangan Sistem Berorientasi Objek Dengan UML. Informatika Bandung, 2018.

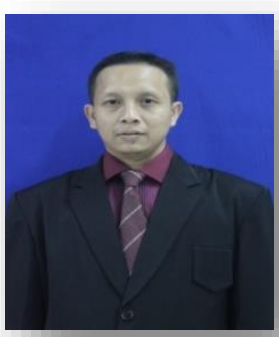

Rachmat Hidayat, Lahir di Jakarta, 27 Januari 1977, Lulus Master Komputer (S2) tahun 2011 STMIK Nusa Mandiri Jakarta, saat ini aktif sebagai staff akademi di Universitas Bina Sarana Informatika.

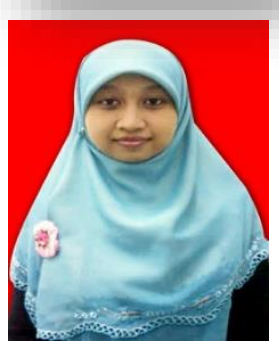

Yusnia Budiarti, Lahir di Tulung Agung, Jawa Timur pada 08 Mei 1987, merupakan dosen tetap di Universitas Nusa Mandiri dan telah menyelesaikan Pendidikan S2 di kampus STMIK Nusa Mandiri Jakarta pada tahun 2014.

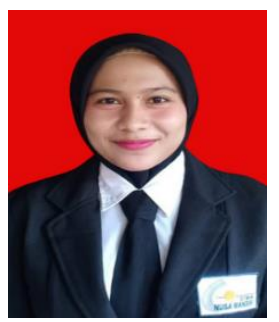

Evita Sulis Tyanur, Lahir di Tegal, Jawa Tengah pada 10 Mei 1997, Lulus tahun 2020 Sarjana Sistem Informasi (S1) STMIK Nusa Mandiri Jakarta, saat ini bekerja sebagai karyawan swasta pada PT Sinar Utama Jaya Abadi sejak tahun 2016 hinga saat ini. 